\title{
PENGARUH GLOBAL TERHADAP HUKUM LINGKUNGAN DI INDONESIA
}

\author{
Susi Yanuarsi \\ Fakultas Hukum Universitas Palembang \\ E-mail: susi.yanuarsi@gmail.com
}

\begin{abstract}
The global environmental problem is a reflection of the international community on the occurrence of environmental damage and pollution that has engulfed the world due to development. Problems can be formulated on how the global impact of international environmental law conventions on environmental law in Indonesia. International conferences in the global environmental field will certainly have an effect on Indonesian legal politics in the environmental field. Government policies ratified various international conventions related to environmental protection. The environmental protection and management policy provides the concept of sustainable environmental development. Existing environmental legal instruments should be consistently enforced especially in the enforcement of environmental law. The importance of awareness of all components of the nation to develop the Indonesian state by relying on sustainable environmental development.
\end{abstract}

Keywords: Global Environment, Environmental Law

\begin{abstract}
Abstrak
Masalah lingkungan hidup global merupakan refleksi masyarakat internasional terhadap terjadinya kerusakan dan pencemaran lingkungan yang melanda dunia akibat adanya pembangunan. Dapat dirumuskan permasalahan pada bagaimana dampak global konvensi hukum lingkungan internasional terhadap hukum lingkungan di Indonesia. Konfrensi-konfrensi internasional di bidang lingkungan hidup global, tentunya akan berpengaruh terhadap politik hukum Indonesia di bidang lingkungan. Kebijakan pemerintah meratifikasi berbagai konvensi internasional yang berkaitan dengan perlindungan terhadap lingkungan. Kebijakan perlindungan dan pengelolaan lingkungan memberikan konsep pembangunan lingkungan yang berkelanjutan. Instrumen hukum lingkungan yang ada hendaknya ditegakkan secara konsisten khususnya dalam penegakan hukum lingkungan. Pentingnya kesadaran dari semua komponen bangsa untuk membangunan negara Indonesia dengan bersandar pada pembangunan lingkungan yang berkelanjutan.
\end{abstract}

Kata Kunci : Lingkungan Hidup Global, Hukum Lingkungan

\section{PENDAHULUAN}

Pembangunan merupakan upaya sadar yang dilakukan oleh manusia untuk mencapai kehidupan yang labih baik. Hakikat pembangunan adalah bagaimana agar hari depan lebih baik dari hari ini. Namun demikian, tidak dapat dipungkiri bahwa pembangunan akan selalu besentuhan dengan lingkungan. Bruce
Mitcel mengatakan pengelolaan sumber daya lingkungan akan mengalami empat situasi pokok yaitu: ${ }^{1}$ (a) Perubahan (change), (b) Kompleksitas (complexity), (c) ketidakpastian (uncertainty) dan (d) konflik (conflict).

1 Supriadi, Hukum Lingkungan di Indonesia Sebuah Pengantar, Jakarta: Sinar Grafika, 2006, hlm. 38 . 
Susi Yaniarsi, Pengaruh Global Terhadap Hukum Lingkungan di Indonesia, Halaman 258-268

Dalam konteks negara Indonesia, hakikat pembangunan menurut Emil Salim $^{2}$ adalah pembangunan manusia Indonesia seutuhnya dan pembangunan seluruh masyarakat Indonesia. Hal ini berarti pemangunan mencakup pertama, kemajuan lahiriah, seperti pangan, sandang, perumahan dan lain-lain; kedua kemajuan batiniah, seperti pendidikan, rasa aman, rasa keadilan, rasa sehat; ketiga kemajuan yang meliputi seluruh rakyat sebagaimana tercermin dalam perbaikan hidup berkeadilan sosial.

Lebih lanjut Emil Salim ${ }^{3}$ mengatakan bahwa sungguhpun pembangunan telah berjalan ratusan tahun di dunia, namun baru pada permulaan tahun tujuh puluhan ini, dunia mulai sadar dan cemas akan pencemaran dan kerusakan lingkungan hidup sehingga mulai menanganinnya secara sungguh-sungguh sebagai masalah dunia.

Masalah lingkungan hidup global merupakan refleksi masyarakat internasional teradap terjadinya kerusakan/pencemaran lingkungan yang melanda dunia akibat adanya pembangunan. Meadow memberikan laporan berbagai masalah yang menimpa banyak negara di dunia dalam sebuah

2 Emil Salim, Lingkungan Hidup dan Pembangunan, Jakarta: Mutiara Sumber Widya, Cetakan 10, 1995, hlm. 11

${ }^{3}$ Ibid laporannya yang berjudul The limits to growth, suatu laporan kepada the club of rome project on the Predicament of mankind. ${ }^{4}$ Dalam laporan tersebut ada lima masalah utama yang memerlukan perhatian global yaitu: kemajuan industrialisasi, pertumbuhan penduduk yang cepat, kekurangan pangan yang meluas, kerusakan sumber daya alam yang tak terbaharui dan pencemaran lingkungan yang menimbulkan pemikiran negara-negara maju membatasi pertumbuhan sedemikan rupa sehingga akibat yang buruk dapat diindahkan.

Penelitian ini mengangkat permasalahan terkait bagaimana dampak global konvensi hukum lingkungan internasional terhadap hukum lingkungan di Indonesia.

\section{PEMBAHASAN}

Untuk meyikapi perubahan global terhadap kerusakan-kerusakan terhadap lingkungan hidup di berbagai belahan bumi, maka para penggiat lingkungan hidup internasional mengadakan pertemuan pertemuan atau konfrensi internasional di antaranya:

\section{A. Deklarasi Stockholm di Swedia}

Dampak dari pembangunan sebagaimana laporan tersebut telah

${ }^{4}$ Ibid 
Susi Yaniarsi, Pengaruh Global Terhadap Hukum Lingkungan di Indonesia, Halaman 258-268

dirasakan oleh masyarakat internasional sebagai masalah yang harus ditangani sedini mungkin. Untuk mengatasi persoalan lingkungan tersebut, pada tanggal 12 Juni 1972 di Stckholm diadakan konfrensi Perserikatan Bangsa-Bangsa (PBB) untuk pembangunan dan lingkungan yang dihadiri oleh kurang lebih 110 negara. Dalam konfrensi tersebut dibicarakan mengenai masalah lingkungan dan jalan keluarnya agar pembangunan tetap terlaksanakan dengan memperhitungkan daya dukung lingkungan.

Salah satu rekomendasi dari konfrensi PBB untuk lingkungan hidup dan pembangunan adalah dibentuknya badan khusus PBB yang mengurusi masalah lingkungan yang disebut Governing Council of Enviromental Programme, yang akhirnya menjadi United Nation Envirment Programme (UNEP).

Konfrensi PBB untuk lingkungan dan pembangunan tersebut secara langsung maupun tidak langsung mempunyai pengaruh yang signifikan terhadap pembangunan lingkungan regional dan nasional. Dalam artian, hasil dari konfrensi PBB untuk lingkungan hidup dan pembangunan harus ditindaklanjuti oleh setiap negara anggota
PBB. Indonesia sebagai salah satu negara anggota $\mathrm{PBB}$ menindaklanjuti dari apa yang dihasilkan oleh konfrensi PBB dalam bidang lingkungan dan pembangunan dengan mengeluarkan Undang-Undang Lingkungan Hidup. Seperti Undang-Undang Nomor 4 Tahun 1982 tentang Ketentuan-Ketentuan Pokok Lingkungan Hidup, yang telah diubah dengan dikeluarkannya Undang-Undang Nomor 23 Tahun 1997 tentang Pengelolaan Lingkungan Hidup dan telah diperbaharui dengan Undang-Undang Nomor 23 Tahun 2009 tentang Perlindungan dan Pengelolaan Lingkungan idup.

Perubahan undang-undang tersebut tidak terlepas dari pengaruh global terhadap hukum lingkungan khususnya akibat dari keluarnya beberapa deklarasi lingkungan seperti deklarasi Stockholm 1972 di Swedia yang menghasilkan 26 asas yang berkaitan dengan lingkungan hidup dan rencana asas lingkungan hidup manusia dan beberapa rekomendasi yang berkaitan dengan lingkungan hidup. ${ }^{5}$ Perkembangan hukum lingkungan tidak dapat dipisahkan dari gerakan sedunia untuk memberikan perhatian lebih besar kepada lingkungan hidup mengingat

\footnotetext{
${ }^{5}$ Harcout Wendy, Globalization if The Economy An International Genger Perspective, dalam Fokus on Gender Vol. 203 Oktober 1994, hlm. 70.
} 
Susi Yaniarsi, Pengaruh Global Terhadap Hukum Lingkungan di Indonesia, Halaman 258-268

kenyataan bahwa lingkungan hidup telah menjadi masalah yang perlu ditanggulangi bersama demi kelangsungan hidup di dunia.

\section{B. Deklarasi Rio De Janeiro Brazil}

Selanjutnya tahun 1992 lahirnya

Deklarasi Rio De Janeiro di Brazil.

Deklarasi Rio De Janeiro merupakan konfrensi PBB mengenai lingkungan hidup yang kedua setelah konfrensi PBB mengenai lingkungan hidup pertama di Stockholm. Konfrensi Rio De Janeiro lazim disebut konfrensi tingkat tinggi bumi, telah menghasilkan 5 Dokumen sebagai berikut:

1. Deklrasi Rio tentang lingkungan dan pembangunan dengan 27 asas yang menetapkan hak dan tanggung jawab bengsa-bangsa dalam memperjuangkan perkembangan dan kesejahteraan manusia.

2. Agenda 21, tentang pembangunan berkelanjutan.

3. Prinsip-prinsip pengelolaan lingkungan.

4. Pengurangan emisi gas-gas karbon.

5. Pelestarian lingkungan.

Hasil konfrensi deklarasi Rio De Janeiro menetapkan serangkaian asas sebagai pedoman pembangunan di masa mendatang. Asas-asas ini menetapkan hak-hak manusia atas pembangunan, dan tanggung jawab manusia teradap pelestarian lingkungan bersama, juga perlu adanya perlindungan lingkungan.

\section{Protokol Kyoto di Jepang}

Prinsip-prinsip Protokol Kyoto 1997. Lahirnya perjanjian Protokol Kyoto muncul karena timbul kekhawatiran para pakar kehutanan dan klimatologi terhadap terjadinya pemanasan global akhir-akhir ini. Pemanasan global ini adalah kabar buruk yang akan menimpa generasi mendatang. Perubahan iklim yang terjadi muncul sebagai dampak dari aktivitas manusia yang melakukan eksploitasi sumber daya alam yang tidak terkendali, yang pada akhirnya menimbulkan pemanasan global yang dirasakan saat ini.

Protokol Kyoto merupakan refpeksi dari keinginan masyarakat dunia untuk mengurangi gas rumah kaca yang terjadi di atmosfer, yang setiap hari semakin meningkat. Peningkatan gas-gas ini telah hampir merata di seluruh dunia dan dampaknya telah terasa saat ini. Oleh karena itu, para pakar lingkungan, para pengamat, dan para kepala negara sepakat untuk melakukan pertemuan secara berkala, yang tujuannya adalah untuk melihat komiten negara-negara maju terhadap emisi karbon. 
Susi Yaniarsi, Pengaruh Global Terhadap Hukum Lingkungan di Indonesia, Halaman 258-268

Protokol Kyoto diratifikasi paling sedikit 55 negara maju, karena negara maju yang paling banyak menyumbangkan emisi karbon. Tetapi tidak semua negara maju yang menyetujui Protokol Kyoto, seperti negara Amerika Serikat menolak Protokol Kyoto dan penolakan ini tidak terlepas dari kepentingan politik dari negara Amerika serikat.

1. Implikasi Protokol Kyoto bagi Indonesia

Indonesia sebagai salah satu negara yang termasuk dalam kategori negara sedang berkembang secara hukum tidak mempunyai kewajiban untuk melakukan pengurangi terhadap emisinya, karena dalam ketentuan Protokol Kyoto, negara berkembang tidak diwajibkan untuk melakukan pengurangi emisinya. Namun demikian, Indonesia sebagai negara yang telah bergabung dalam masyarakat dunia di bawah payung PBB sangat berpengaruh kalau ikut meratifikasi Protokol Kyoto tersebut. Karena Protokol Kyoto menurut Daniel Murdiyrso ${ }^{6}$ ilmplikasinya dapat dikelompokan dalam tiga aspek yaitu: politik dan hukum, bisnis dan kelembagaan.

\section{Implikasi Pada Politik dan Hukum}

${ }^{6}$ Supriadi, Op.Cit, hlm, 72
Secara hukum, ratifikasi atau pengesahan suatu konvensi tidak selalu ditindaklanjuti dengan pengesahan protokolnya. Jika ternyata ada negara yang mengesahkan konvensi, tetapi menolak protokolnya, itu adalah hak negara tersebut karena menurut pertimbangannya terdapat hal-hal yang merugikan. Dengan kata lain, perlu tidaknya pengesahan adalah kedaulatan setiap negara yang didasari berbagai pertimbangan, termasuk pertimbangan-pertimbangan politik, hukum nasional dan finansial serta peluang melakukan pengembangan bisnis.

Salah satu sektor yang diatur dalam Protokol Kyoto adalah di sektor energi. Untuk mengimlementasikan sektor-sektor yang akan mendapat bantuan dari organisasi para pihak sesuai Protokol Kyoto tersebut, negara berkembang harus memiliki perangkat hukum di bidang energi yang bersifat komprehensif. ${ }^{7}$ Indonesia sebenarnya telah memiliki beberapa peraturan perundang-undangan yang mengatur energi seperti: Undang-Undang Nomor 22 Tahun 2001 tentang Minyak dan Gas Bumi dan Undang-Undang Nomor 20 Tahun 2002 tentang Ketenagalistrikan.

\footnotetext{
7 Abdul Manan, Aspek-aspek Penguba Hukum,
} Jakarta: Kencana Prenada Media, 2006, hlm . 29. 
Susi Yaniarsi, Pengaruh Global Terhadap Hukum Lingkungan di Indonesia, Halaman 258-268

Hingga saat ini Indonesia belum memiliki undang-undang yang mengatur energi secara komprehensif dan menangani berbagai sumber energi

Di sektor lingkungan Indonesia memiliki instrumen hukum seperti Undang-Undang Nomor 4 Tahun 1982 tentang Ketentuan-Ketentuan Pokok Pengelolaan Lingkungan sebagaiman telah diubah dengan Undang-Undang Nomor 23 Tahun 1997 tentang Pengelolaan Lingkungan Hidup yang baru diubah dengan Undang-Undang Nomor 32 Tahun 2009 tentang Perlindungan dan Pengelolaan Lingkungan Hidup. Perubahan Undang-Undang di bidang lingkungan tersebut tidak terlepas dari pengaruh global di bidang lingkungan hidup, karena masing-masing undang-undang tersebut memiliki oreintasinya. ${ }^{8}$

Di samping itu ada beberapa peraturan yang berkaitan dengan lingkungan hidup, seperti Undang-Undang Agraria Nomor 5 Tahun 1960, Undang-Undang Kehutanan Nomor 41 Tahun 1999, Undang-Undang Perkebunan Nomor 18 Tahun 2004, Undang-Undang Pertanian Nomor 4 Tahun 2009, Undang-Undang Sumber

8 Soemitro Ronni Hanitijio, Problema Globalisasi. Surakarta: Muhammadiyah University Pers, 2001, hlm. 61.
Daya Air Nomor 7 Tahun 2004, Undang-Undang Nomor 4 Tahun 2009 tentang Pertambangan dan undang-undang lainnya yang memiliki hubungan dengan bidang lingkungan hidup.

\section{Bisnis}

Implikasi pada sektor bisnis ini berkaitan dengan terjadinya penawaran pasar karbon global yang berhubungan dengan penurunan emisi. Untuk mencapai target penurunan emisinya, negara-negara industri dapat melakukan secara domestik, tetapi dapat dipastikan bahwa cara tersebut akan memakan biaya tinggi. Oleh karena itu, mereka akan pergi pasar karbon global luar negeri melalui proyek-proyek investasi baru di berbagai sektor dengan menggunakan mekanisme Kyoto. Sektor-sektor yang dapat menurunkan emisi antara lain, energi, industri, transportasi, kehutanan, pertanian, dan limbah domestik. Bagi Indonesia terbuka peluang investasi. Peluang Indonesia dalam pasar karbon global hanya 2 persen. ${ }^{9}$

\section{Kelembagaan}

Langkah awal yang harus dilakukan semua negara yang ingin berpartisipasi dalam kegiatan CDM (clean development

\footnotetext{
9 Muhammad Taufik Makarao, Aspek-Aspek Hukum Lingkungan, Jakarta: PT. Indeks Kelompok Gramedia, 2006, hlm. 134.
} 
Susi Yaniarsi, Pengaruh Global Terhadap Hukum Lingkungan di Indonesia, Halaman 258-268

mechanism), termasuk Indonesia adalah mengesahkan Protokol Kyoto. Dengan menyusun peraturan perundang-undangan yang akan berlaku secara nasional, maka ditindaklanjuti oleh pemerintah provinsi, kabupaten dan kota, sehingga memberikan daya tarik untuk berinvestasi. ${ }^{10}$

D. Konfrensi Tingkat Tinggi (KTT) Pembangunan Berkelanjutan di Johannesburg, Afrika Selatan

$\begin{array}{rrr}\text { Konfrensi } & \text { tingkat } & \text { tinggi } \\ \text { pembangunan } & \text { berkelanjutan } & \text { yang }\end{array}$ dilaksanakan di Johannesburg Afrika Selatan pada tahun 2002, merupakan lanjutan konfrensi yang pertama di Stockholm Swedia pada tahun 1972 dan konfrensi kedua di Rio De Janeiro Brazil tahun 1992. Konfrensi di Johannesburg Afrika Selatan ini lebih memfokuskan pada pembangunan berkelanjutan. Pembangunan berkelanjutan meliputi: pembangunan ekonomi, pembangunan sosial dan perlindungan lingkungan, sebagai pilar yang saling tergantung dan saling memperkuat satu sama lain.

Pengaruh konfrensi di Johannesburg Afrika Selatan bagi Indonesia adalah meliputi:

10 Syaifudddin Ateng, Penataan Ruang dan Lingkungan Hidup dalam Kaitannya dengan Wewenang Pemerintah Daerah, Makalah Hukum Lingkungan, Fakultas Hukum Unair, Surabaya, 1992. hlm 85 .
1. Penghapusan kemiskinan;

2. Mengubah pola konsumsi dan produksi yang tidak berkelanjutan (sayur dan buah Indonesia sulit menembus pasar global karena mengandung insektisida);

3. Melindungi dan mengelola basis sumber daya alam bagi pembangunan ekonomi dan sosial;

4. Program pembangunan kelautan dan pesisir (dilarang menggunakan alat pengangkapan ikan pakai pukat harimau atau pakai bom);

5. Perubaan iklim dan penanganan bencana;

6. Program mengatasi pencemaran udara dan pembangunan pertanian (diwajibkan untuk menanam pohon-pohon, karena sebagai paru-paru dunia);

7. Pembangunan berkelanjutan dalam era globalisasi; dan

8. Kesehatan dan pembangunan berkelanjutan.

\section{E. Konvensi Internasional}

Di samping berbagai instrumen hukum lingkungan sebagaimana dikemukakan di atas, ada perjanjian dan konvensi internasional di bidang lingkungan merupakan instrumen baru bagi kebijaksanaan lingkungan yang realistik. Begitu pula halnya dalam 
Susi Yaniarsi, Pengaruh Global Terhadap Hukum Lingkungan di Indonesia, Halaman 258-268

perkembangan pengelolaan lingkungan di Indonesia, beberapa konvensi internasional yang telah diratifikasi mempunyai implikasi yang penting bagi pembangunan peraturan perundang-undangan lingkungan nasional. Berikut ini dikemukakan beberapa konvensi dan perjanjian internasional yang telah diratifikasi oleh Indonesia sebagai pengaruh dari globalisasi terhadap pengelolaan lingkungan di Indonesia. ${ }^{11}$

1. Keputusan Presiden Nomor 18 Tahun 1978 tentang Pengesahan International Convention on Civil Liability for Oil Pollution Damage 1969 jo. Keputusan Presiden Nomor 52 Tahun 1999 tentang Pengesahan Protocol of 1992 to Amend the International Convention on Civil Liablity for All Pollution Damage 1969. (Protokol 1992 tentang Perubahan Terhadap Konvensi Internasioal tentang Tanggung Jawab Perdata Kerusakan Akibat Pencemaran Minyak, 1969).

2. Keputusan Presiden Nomor 43 Tahun 1978 tentang Pengesahan Convention on International Trade in Endangered

${ }^{11}$ Siti Sundari Rangkuti, Hukum Lingkungan dan Kebijaksaaan Lingkungan Nasional, Edisi Ketiga, Surabaya: Airlangga University Press, 2005, hlm. 118.
Species of Wild Fauna and Flora (CITES), 1973.

3. Undang-Undang Nomor 17 Tahun 1985 tentang Ratifikasi United Nations Convention on The Law of The Sea (UNCLOS) 1982. Konvensi ini mempunyai kekuatan berlaku tanggal 16 November 1994. Sebagai perangkat hukum pendukung berlaku Undang-Undang Nomor 6 Tahun 1996 tentang Perairan Indonesia dan PP Nomor 19 Tahun 1997 tentang Pengendalian Pencemaran dan/atau Perusakan Laut.

4. Keputusan Presiden Nomor 26 Tahun 1986 tentang Pengesahan ASEAN Agreement on The Conservation of Nature and Natural Resources, 1985. Peraturan perundang-undangan nasional masing-masing negara anggota hendaklah menampung ketentuan-ketentuan yang menjamin konservasi dan pengelolaan sumber daya alam sebagai bagian integral dari perencanaan pembangunan.

5. Keputusan Presiden Nomor 46 Tahun 1986 tentang Pengesahan International Convention for the Prevention of Pollution from Ships, 1973, beserta Protokol (The Protocl of 1978 Relating to The International Convention for The Prevention of 
Susi Yaniarsi, Pengaruh Global Terhadap Hukum Lingkungan di Indonesia, Halaman 258-268

Pollution from Ships, 1973). Untuk menjaga kelestarian lingkungan laut dari bahaya pencemaran yang berasal dari pengoperasian kapal-kapal.

6. Keputusan Presiden Nomor 26 Tahun 1989 tentang Pengesahan Convention Concerning The Protection of The Word Cultural and Natural Heritage. Dengan mengeluarkan Undang-Undang Nomor 5 Tahun 1992 tentang Benda dan Cagar budaya.

7. Keputusan Presiden Nomor 48 Tahun 1991 tentang Pengesahan Convention on Wetlands of International Importance Especially as Waterfowl Habitat. Konvensi tersebut bertujuan melestarikan lahan basah berikut flora dan faunanya yang pelaksanaannya memerlukan keterpaduan antara kebijaksanaan nasional dan kebijaksanaan internasional.

8. Keputusan Presiden Nomor 23 Tahun 1992 tentang Pengeshan Convention for The Protection of The Ozone Layer and Manterial Protocol on Substannce The Deplete The Ozone layer as Adjusted and Amended by The Second Meeting of The Parties, (London 27-29 June 1990). Konvensi ini berkaitan dengan perlindungan lapisan ozon.
9. Keputusan Presiden Nomor 61 Tahun 1993 tentang Pengesahan Basel Convention on The Control of Transboundary Movements of Hazardous Wastes and Their Disposal. Tujuan konvensi ini agar wilayah Indonesia tidak menjadi tempat pembuangan limbah berbahaya dari luar negari.

10. Keputusan Presiden Nomor 135 Tahun 1998 tentang Pengesahan The United Nations Convention to Combat Desertification in Those Countries Experiencing Serious Drought and/or Desertification, Particulary in Africa (konvensi perserikatan bangsa-bangsa untuk memerangi penggurunan di negara-negara yang mengalami kekeringan dan/atau penggurunan yang serius, terutama Afrika, tanggal 20 Agustus 1998).

11. Undang-undang Nomor 5 Tahun 1994 tentang Pengesahan United Nations Convention on Biological Diversity (konvensi perserikatan bangsa-bangsa mengenai keanekaragaman hayati).

12. Undang-Undang Nomor 6 Tahun 1994 tentang Pengesahan United Nations Framework Convention on Climate Change (konvensi kerangka 
Susi Yaniarsi, Pengaruh Global Terhadap Hukum Lingkungan di Indonesia, Halaman 258-268

kerja perserikatan bangsa-bangsa mengenai perubahan iklim).

13. Undang-Undang Nomor 9 Tahun 1997 tentang Pengesahan Treaty on The Southeast Asia Nuclear Weapon Freezone (Traktat kawasan bebas senjata nuklir di Asia Tenggara).

14. Undang-Undang Nomor 6 Tahun 1998 tentang Pengesahan Convention on The Prohibition of The Development, Production, Stockpiling and us of Chemical Weapon and Their Destruction yakni konvensi tentang larangan pengembangan, produksi penimbunan dan penggunaan senjata kimia serta tentang pemusnahannya.

Berbagai konvensi yang telah ditandatangani atau telah diratifikasi oleh negara Indonesia, merupakan pengaruh global terhadap lingkungan, sehingga negara-negara, baik negara maju maupun negara berkembang tentunya memiliki kepentingan untuk menjaga dan melestarikan lingkungan, sehingga kemanfaatan pengelolaan lingkungan tersebut berguna untuk generasi mendatang dan disamping itu juga perlunya adanya kesadaran dari semua komponen bangsa untuk membangunan negara Indonesia dengan konsep pembangunan lingkungan yang berkelanjutan.

\section{PENUTUP}

Konfrensi-konfrensi internasional di bidang lingkungan hidup global, tentunya akan berpengaruh terhadap politik hukum Indonesia di bidang lingkungan hal ini dapat dilihat dari kebijakan pemerintah meratifikasi berbagai konvensi internasional yang berkaitan dengan perlindungan terhadap lingkungan. Di samping meratifikasi berbagai konvensi internasional tersebut, pemerintah Indonesia juga mengeluarkan beberapa peraturan perundang-undangan di bidang lingkungan seperti Undang-Undang Nomor 32 Tahun 2009 tentang Perlindungan dan Pengelolaan Lingkungan Hidup dan beberapa peraturan perundang-undangan yang memiliki hubungan dengan lingkungan hidup, seperti undang-undang wilayah perairan, undang-undang perkebunan, undang-undang kehutanan, undang-undang pertanian, undang-undang tentang migas, undang-undang tentang sumber daya air, undang-undang kelistrikan dan undang-undang agraria sebagai induk dari peraturan perundang-undangan di bidang lingkungan hidup yang memuat nilai filosofis bagi pengelolaan setiap sumber kekayaan alam yang ada di Indonesia. 
Susi Yaniarsi, Pengaruh Global Terhadap Hukum Lingkungan di Indonesia, Halaman 258-268

Instrumen hukum lingkungan yang ada hendaknya ditegakkan secara konsisten khususnya dalam penegakan hukum lingkungan berkaitan dengan emisi karbon yang berdampak terhadap pencemaran lingkungan dengan menerapkan sertifikasi terhadap pabrik-pabrik yang mencemari udara.

\section{DAFTAR PUSTAKA}

Abdul Manan, Aspek-Aspek Pengubah Hukum, Jakarta: Kencana Prenada Media, 2006.

Emil Salim, Lingkungan Hidup dan Pembangunan, Cetakan 10, Jakarta: Mutiara Sumber Widya, 1995.

Harcout Wendy, Globalization if The Economic An International Gender Perspectice, dalam Fokus Gender Vol. 2 No. 3 Oktober 1994.

Muhammad Taufik Makarao, Aspek-aspek Hukum Lingkungan, Jakarta: PT. Indeks Kelompok Gramedia, 2006.

Salim H.S. Dasar-Dasar Hukum Kehutanan, Jakarta: Sinar Grafika, 2004.

Siti Sundari Rangkuti, Hukum Lingkungan dan Kebijaksaaan Lingkungan Nasional, Edisi Ketiga, Surabaya: Airlangga university press, 2005.
Soemitro Ronni Hanitijio, Problema Globalisasi. Surakarta: Muhammadiyah University Pers, 2001.

Supriadi, Hukum Lingkungan di Indonesia Suatu Pengantar, Jakarta: Sinar Grafika, 2006.

Syaifudddin Ateng, Penataan Ruang dan Lingkungan Hidup dalam Kaitannya dengan Wewenang Pemerintah Daerah, Makalah Hukum Lingkungan, Fakultas Hukum Unair, Surabaya, 1992. 